\title{
Romanian National Guidelines on Contrast Enhanced Ultrasound in clinical practice
}

\author{
Ioan Sporea ${ }^{1}$, Radu Badea ${ }^{2}$, Ciprian Brisc ${ }^{3}$, Simona Ioanițescu ${ }^{4}$, Tudor Moga ${ }^{1}$, \\ Alina Popescu ${ }^{1}$, Adrian Săftoiu ${ }^{5}$, Larisa Săndulescu ${ }^{5}$, Zeno Spârchez ${ }^{6}$, Roxana Șirli ${ }^{1}$
}

${ }^{1}$ Department of Gastroenterology and Hepatology, „Victor Babeș” University of Medicine and Pharmacy Timișoara, 2Department of Ultrasound, 3rd Medical Clinic, „Octavian Fodor” Institute of Gastroenterology and Hepatology, „Iuliu Hațieganu” University of Medicine and Pharmacy Cluj Napoca, ${ }^{3}$ Department of Gastroenterology, University of Oradea, ${ }^{4}$ Department of Internal Medicine, Fundeni Clinical Institute \& "Carol Davila" University of Medicine and Pharmacy Bucharest, ${ }^{5}$ Department of Gastroenterology, Research Center of Gastroenterology and Hepatology Craiova, University of Medicine and Pharmacy Craiova, '3rd Medical Deparment, „Octavian Fodor” Institute of Gastroenterology and Hepatology, „Iuliu Hațieganu” University of Medicine and Pharmacy Cluj Napoca, Romania

\section{Abstract}

Contrast-enhanced ultrasound (CEUS) allows a real-time assessment of the vascular pattern of different types of lesions, as it has no renal or liver toxicity, it lacks radiation exposure and it is also cheaper than other imaging methods, having a diagnostic capability that matches contrast-enhanced CT or MRI. In Romania CEUS is used more and more, especially by clinicians, and since some centres have extensive experience in this domain, we felt the need to disseminate our expertise in order to implement this method in as many centres as possible. These Guidelines present the clinical applications of CEUS in the liver, spleen, pancreas, kidney, testis, bowel, intra-cavitary and endoscopic ultrasound, as well as other applications.

Keywords: Contrast Enhanced Ultrasound; guidelines; clinical applications

\section{Introduction}

Following the introduction of ultrasound contrast agents (UCA), the ultrasonography method has gained a diagnostic capability that matches contrast-enhanced CT or MRI (CECT or CEMRI) [1-3]. A true benefit is seen in patients with contraindications for CECT or CEMRI, such as renal failure or claustrophobia. Contrast-enhanced ultrasound (CEUS) has many advantages: it allows a real-time assessment of the vascular pattern, in different vascular phases [4]; it has no renal or liver toxicity; it lacks radiation exposure; it is also cheaper than other imaging methods and does not need additional specialized personnel, aside from the operator. The limi-

Received Accepted

Med Ultrason

2017, Vol. 19, No 4, 401-415

Corresponding author: Prof. Dr. Ioan Sporea

13, Snagov str., 300482 Timişoara

Tel: +40-748099963

E-mail: isporea@umft.ro tations of CEUS are those of conventional ultrasound (US). In order to obtain the best results, CEUS must always be corroborated with clinical data and with the standard US examination [5].

Second generation UCA consist of microbubbles approximately the same size as the red blood cells, filled with an inert gas and stabilized by a shell with a short half-life. The UCA used in Europe is SonoVue ${ }^{\circledR}$ (Bracco, Italy), that contains sulphur hexafluoride with a phospholipid shell [6]. To perform CEUS dedicated software is needed, able to perform low mechanical index (MI) examination, during which microbubbles will show a nonlinear response, as opposed to the linear one of the surrounding tissues, whilst under high MI bubbles will burst. CEUS should be performed by an experienced operator, at least level II according to the European Federation of Societies in Ultrasound and Medicine (EFSUMB) classification [7].

An informed consent must be obtained before performing CEUS, even if CEUS is a safe method with very 
few side effects [8]. There are limited data regarding the use of CEUS in pregnancy and breastfeeding.

Intravenous access on the left antecubital vein, by at least a 20-gauge cannula, is preferred. The injection of UCA $(1-2.4 \mathrm{ml} /$ examination for liver CEUS $)$ is followed by a $10 \mathrm{ml}$ saline flush. A timing counter on the ultrasound machine should be available to monitor the vascular phases described for the liver: arterial phase - starting 10 seconds after the contrast bolus, lasting 30 seconds; portal phase: $30-120$ seconds following the contrast bolus; and the late phase, starting 120 seconds following the contrast bolus, lasting until the total disappearance of the bubbles [5]. Only two phases, arterial phase - starting 10-15 seconds from contrast bolus; and venous phase - starting 30 seconds following contrast bolus, are described for other organs, for e.g. spleen, pancreas, gastrointestinal (GI) tract wall, etc. The enhancement patterns of structures evaluated by CEUS are described as hyper-, iso-, hypo-, or non-enhancing as compared with the surrounding tissues.

In Romania CEUS is used more and more, especially by clinicians, and since some centres have extensive experience in this domain, we felt the need to disseminate our expertise in order to implement this accurate, nontoxic, inexpensive method in as many centres as possible. These Guidelines present the clinical applications of CEUS in the liver, spleen, pancreas, kidney, testis, bowel, intra-cavitary and endoscopic ultrasound, as well as other applications.

\section{Liver}

CEUS should be performed after conventional and Doppler US examinations. The clinical and biological background of the patient should be known, since comorbidity with liver cirrhosis influences the diagnostic approach. CEUS is used to evaluate focal liver lesions (FLL), to monitor oncologic patients, to follow-up treatment results, to guide core biopsy in hepatic tumors and others. The main indications for liver CEUS are to characterize FLL in the next scenarios: a) an incidental FLL detected by US; b) a newly detected lesion on a cirrhotic liver; c) FLL inconclusive after either CECT or CEMRI; d) follow-up of inconclusive lesions; e) guidance of FLL biopsy; f) follow-up of previously treated FLLs in order to evaluate the therapeutic response or disease progression $[5,9]$.

CEUS has proved to be a very good method for FLL characterization. In a meta-analysis of Friedrich-Rust that included 7231 FLLs, CEUS had a general sensitivity of $93 \%$ and $90 \%$ specificity for differentiating benign vs. malignant lesions. There were no significant differences between CEUS and CECT/CEMRI regarding specificity $(88 \%$ vs. $83 \%, p=0.11)$ and sensitivity $(95 \%$ vs. $89 \%$, $\mathrm{p}=0.033$ ) [10]. Other published studies showed that CEUS has a sensitivity higher than $90 \%$ for diagnosing malignancy $[2,11-13]$.

In another meta-analysis, CEUS was compared with CECT and CEMRI for FLL characterization and had a pooled sensitivity of $88 \%$ (the highest among the three), and a pooled specificity of $81 \%$ [3].

The same good results were found in a Romanian multicenter study: when only cases categorized as conclusive for benign/malignant differentiation were taken into consideration, CEUS had $95.7 \%$ sensitivity, $96.4 \%$ specificity, $98 \%$ positive predictive value, $92.6 \%$ negative predictive value, and $96 \%$ accuracy [13]

Hemangiomas are the most common benign liver tumors [14]. On US, their typical aspect is hyperechoic homogeneous round lesions with distinct margins [15]. The typical CEUS pattern of hemangiomas is globular enhancement in the periphery in the arterial phase, with progressive centripetal fill-in. During the late phase, the centripetal fill-in appears complete in $40-50 \%$ of cases, with a persistent hyper- or isoechogenicity [5].

CEUS is a highly accurate method for characterization of liver hemangiomas (accuracy >94\%) [12,16-17], with sensitivities ranging from $62.5 \%$ in the DEGUM multicenter study [18] to $90.4 \%$ in a Romanian multicenter study [16], with a calculated pooled sensitivity of $86 \%$ in the Friedrich-Rust meta-analysis [10]. The specificity can be as high as $99 \%$ [17].

Focal Nodular Hyperplasia (FNH) is the second most common benign FLL. It is a regenerative mass of variable size, resulting from a vascular abnormality - an abnormal feeding artery that generates a hyperplastic response from the hepatocytes [19]. There is no specific grey-scale appearance in FNH. It can be hypoechoic, isoechoic, or slightly hyperechoic, with a central scar appearing as hyperechoic [20]. Colour Doppler enables visualisation of the feeding artery and the ,spoke-wheel” vascular pattern. On CEUS, in the arterial phase, a rapid (or very rapid) fill-in from the centre outwards (70\%) or with an eccentric vascular supply $(30 \%)$ can be seen. During the portal and late phases, FNHs remain hyperenhancing or become isoenhancing, sometimes with the visualisation of a central hypoechoic scar [5]. CEUS is an accurate method to characterise FNH with $95.5 \%$ general accuracy in the DEGUM study [18], and $98.5 \%$ in the Romanian multicenter study [21]. In the STIC study, CEUS had $82.5 \%$ sensitivity and $94.3 \%$ specificity for the diagnosis of FNH [22], while in the DEGUM study they were $57.1 \%$ and $99.3 \%$, respectively [18]. The calculated pooled sensitivity for FNH was $88 \%$ in the Frie- 
drich-Rust meta-analysis [10] and the specificity can go as high as $100 \%[12,23]$.

Adenoma is a rare benign liver tumor, more frequent in young women and in people using steroid containing drugs [24]. In conventional US, adenomas can be hyperechoic, hypoechoic, isoechoic, or inhomogeneous [25]. On CEUS, adenoma usually shows homogeneous arterial hyperenhancement, initially at the periphery with a very rapid centripetal filling, the opposite to that seen in FNH. In the early portal venous phase, it usually becomes isoechoic or, more rarely, remains slightly hyperechoic. Sometimes, wash-out occurs in the late phase, thus being false positive for malignancy [5].

Imaging diagnosis of adenoma is difficult, regardless of the method used, and often guided biopsy is needed for a definite diagnosis. Nevertheless, in the DEGUM study CEUS correctly diagnosed $57.9 \%$ of the adenomas [2].

Focal fatty liver alterations. On conventional US, they appear as hyperechoic areas in a normal liver (focal steatosis) or as hypoechoic areas in a fatty, hyperechoic liver (focal sparing), without mass effect and usually irregular delineation. Their pathogenesis is probably linked to arterio-portal and venous abnormalities [26]. On CEUS, they are isoenhancing as compared to the surrounding liver in all vascular phases [5]. In a Chinese study the reported sensitivity of CEUS in the diagnosis of focal fatty alterations was $88 \%$ and its overall accuracy was $96 \%$ [27]. In a Polish study, CEUS had $95.8 \%$ sensitivity, $100 \%$ specificity and $99.6 \%$ accuracy to diagnose focal fatty liver infiltrations, while for focal fatty sparing the sensitivity was $91.2 \%$, the specificity $100 \%$, with 99.4\% accuracy [28]. In the Romanian multicentre study, CEUS had $96.6 \%$ sensitivity, $86.7 \%$ specificity and $87.3 \%$ accuracy to diagnose focal fatty alterations [13].

Liver abscess. The US appearance varies, usually as a hypoechoic mass with irregular thick walls, internal septa and sometimes gas inside [29]. Clinical information is certainly important. CEUS criteria for the diagnosis of liver abscesses are: marginal rim enhancement in the arterial phase, with enhancement of the septa due to inflammation ("honeycomb" appearance), with no enhancement in the anechoic, liquid areas. Later, during the venous phase, hypoenhancement of the wall and septa can be seen [5]. CEUS is helpful to delineate avascular areas inside the abscess, in order to guide percutaneous drainage [30-32]. In some cases, direct intracavitary injection of UCA allows the assessment of a correct positioning of the needle or catheter, and detects possible communication between cavities in complex abscesses $[33,34]$. In the Romanian multicentre study, CEUS had $76.9 \%$ sensitivity, $88.9 \%$ specificity and $86.9 \%$ accuracy to diagnose liver abscesses [13].
Metastases. Their typical US appearance is of a "target" lesion, but they can also be hyperechoic, hypoechoic or isoechoic. Most liver metastases are hypoenhancing during the arterial phase on CEUS, sometimes with a rim enhancement $[5,35,36]$. Hypervascular metastases show arterial hypenhancement, with quick "wash-out" in the portal phase $[5,37,38]$. Reported sensitivities and specificities for CEUS for the diagnosis of liver metastases range from $80 \%$ to $95 \%[9,39,40]$. Characteristic for the majority of liver metastases is early and progressive "wash-out", started at the end of the arterial phase [5]. In the Romanian multicentre study, CEUS demonstrated $87.1 \%$ sensitivity, $82.9 \%$ specificity and $83.7 \%$ accuracy in diagnosing liver metastases [13]. In the FriedrichRust meta-analysis, the overall sensitivity was $91 \%$ [10]. CEUS has similar performances in detecting liver metastasis as CT and MRI [39,41].

Hepatocellular carcinoma (HCC) is a primary malignant hepatic tumor that usually occurs in high-risk patients (chronic liver disease with severe fibrosis or cirrhosis). US is considered to be the imaging method for screening in order to detect early HCC [42]. Due to its development process, from regenerative nodule to dysplastic nodule with $\mathrm{HCC}$ foci, to well or poorly differentiated $\mathrm{HCC}$, it may present variations in the enhancing pattern at CEUS $[5,43,44]$. Often HCCs are hyperenhanced in the arterial phase, with an irregular or a chaotic pattern [45] that is influenced by the lesion's size [46] with mild, late, or very late "wash-out". The timing of "wash-out" is correlated with the differentiation of the tumor, therefore CEUS examination of the HCC should take a least fourfive minutes [47-49]. Specific algorithms have been developed, such as CEUS LI-RADS [https://www.acr.org/ Quality-Safety/Resources/LIRADS/CEUS-LIRADS], in order to standardize the reporting system and the diagnostic decision in HCC. It is important to keep in mind that a new lesion on a cirrhotic liver, hyperenhancing in the arterial phase on CEUS, is probably HCC [50,51]. In the DEGUM study, CEUS managed a correct diagnosis of HCC in $84.9 \%$ of the cases [18], while in the Romanian multicentre study the accuracy was $90.2 \%$ [13].

In a meta-analysis which evaluated the sensitivity and positive predictive value (PPV) of CEUS, CECT and CEMRI for the detection of HCC, CEUS had $84.4 \%$ sensitivity, CT $76.3 \%$ and MRI $85.6 \%$. The PPV was $89.3 \%$ for CEUS, $85.8 \%$ for CT and $94.2 \%$ for MRI [52]. In the STIC study, CEUS for HCC diagnosis had $69.8 \%$ sensitivity and $94.7 \%$ specificity [22]. In the meta-analysis of Friedrich-Rust, the overall sensitivity for the diagnosis of HCC was $88 \%$ [10].

Intrahepatic cholangiocellular carcinoma (ICC) is a malignant tumor derived from the intrahepatic bile ducts, 
usually occurring in non cirrhotic liver, and much more rarely in cirrhosis (only $1-2 \%$ on the newly diagnosed nodules) [53-55]. ICC appears on standard US as a poorly delineated tumor that has a hypoechoic-heterogeneous aspect $[56,57]$. The imaging diagnosis of ICC is difficult, no matter the technique used (CECT, CEMRI, or CEUS), since it can be misdiagnosed as HCC, especially in cirrhosis [53]. On CEUS, the most common aspect of ICC is of a rim-like hyperenhancing lesion in the arterial phase, with early "wash-out" in the portal phase [58-60], as opposed to CECT, where late "wash-out" does not occur, due to the accumulation of the CT contrast agent in the fibrous stroma $[61,62]$. On the other hand, HCC appears as homogenous, hyperenhanced in the arterial phase, with "wash-out" or isoenhancing pattern in the late phase [63]. In a Spanish study, a similar vascular pattern of ICC and HCC was observed in half cases [64]. However, several studies support the use of CEUS for diagnosing ICC. In the study of Chen et al CEUS showed the same accuracy as CECT [65]. In a subanalysis of the DEGUM study, CEUS managed a correct diagnosis for ICC in $95.2 \%$ of cases [66]. According to a Chinese study, most ICCs $(87.9 \%)$ show "wash-out" in the first 60 seconds, and all of them 3 minutes after the contrast bolus [67] and, based on these criteria, CEUS had $78.8 \%$ sensitivity, $88 \%$ specificity and $84.3 \%$ accuracy for diagnosing ICC [68]. In the Romanian multicentre study, CEUS had $60 \%$ sensitivity, $85.1 \%$ specificity and $83.9 \%$ accuracy for diagnosing ICC [13].

\section{Recommendations:}

a. Liver CEUS is very accurate in the differentiation between benign and malignant FLLs;

b. CEUS has a high accuracy for the diagnosis of hemangiomas, FNHs, focal fatty alterations and liver metastasis. For adenomas, HCCs or ICCs diagnosis is more difficult.

\section{Spleen}

The spleen is involved in many clinical conditions and the use of CEUS considerably increases the diagnostic confidence in comparison with conventional US [69].

Focal splenic lesions (FSLs). CEUS is able to reveal underlying splenic lesions and differentiate between infarcted areas, abscesses and splenic tumour infiltrations mimicking infarction [70,71]. Hyperechoic FSLs incidentally detected on US are in most cases benign. CEUS improves the differentiation between benign and malignant FSLs especially for isoechoic or hypoechoic incidental lesions, unclear on conventional US [72]. Benign FSLs typically appear as nonenhancing in all phases (cystic lesions, infarcted areas) or show rapid enhance- ment followed by persistent late-phase enhancement (solid lesions). Malignant FSLs usually show early diffuse or peripheral enhancement, followed by "wash-out" in the late phase, with progressive hypo-enhancement $[70,72,73]$. In some cases the behaviour of malignant and benign lesions overlap, and benign lesions as haemangiomas, hamartomas, or other uncommon splenic abnormalities show some degree of "wash-out", mimicking a malignant pattern [70,74]. In such cases the analysis of the patient's medical history and complementary investigations are necessary. Splenic metastases are very rare and appear in the late stages of a known malignancy [75]. Some splenic metastases are hyperechoic on conventional US and can have a complex pattern on CEUS, but the clinical context is clear and the diagnosis is already set.

Splenic infarction. CEUS is useful for better delineation of splenic infarction when it is suspected clinically or on conventional US. The infarcted areas are completely non-enhancing on CEUS and usually more extensive than the inhomogeneous areas seen on conventional US. Commonly they have typical "wedge-shaped" appearance, but there are situations when they can mimic FSLs [76-78]. The complete lack of enhancement on CEUS confirms the diagnosis [78,79]. Splenic infarction has a high tendency to spontaneous healing [80] and CEUS can be successfully used for follow-up until complete resorption.

Accessory spleens or splenosis. The ectopic splenic tissue has the same behaviour on CEUS as the normal spleen and can be differentiated from other abdominal lesions due to its particular long-lasting late enhancement [81-85].

Malignant lesions. CEUS is useful for the detection of malignant FSLs in oncologic patients, when CECT and/or CEMRI and/or PET are contraindicated or inconclusive. Studies showed $90 \%$ sensitivity and $100 \%$ specificity as compared to CECT with respect to lesion detection in lymphoma patients [86] and increased the detection rate of metastases by $38 \%$ as compared to splenic conventional US [75]. In monitoring response to chemotherapy, the positive results are seen earlier on CEUS compared to PET-CT [70].

\section{Recommendations:}

a. CEUS is very useful in the characterization of splenic parenchymal inhomogeneity and for accurate delineation of splenic infarction.

b. CEUS improves the detection of splenic malignant lesions in oncologic patients.

c. CEUS improves the differentiation between benign and malignant FSLs. Clinical context should always be considered in overlapping imaging situations. 


\section{Pancreas}

CEUS of the pancreas is performed by scanning the area on interest in the arterial and late phases [70]. In the arterial phase, the pancreas shows a homogeneous intense enhancement due to its rich vascularity, followed by a rapid loss of UCA, at 2 minutes the pancreas appearing as hypoenhancing as compared to the nearby liver [87].

CEUS can be used to characterize focal pancreatic lesions, either solid or cystic, and for the assessment of pancreatic vascularity.

Solid focal pancreatic lesions. Pancreatic ductal adenocarcinoma is usually hypoenhancing in the early phase as compared to the adjacent pancreatic tissue [88-91]. CEUS also allows a better delineation of the tumor and the assessment of vascular invasion $[88,92,93]$. By contrast, neuroendocrine tumors have an intense enhancement in the arterial phase [37,38]. For both types of lesions, CEUS is useful for detecting liver metastases in the late phase ("wash-out" of liver lesions). Several studies proved the utility of CEUS for the characterization of pancreatic tumors [94-98]. The accuracy for the diagnosis of solid pancreatic lesions varies from $91.7 \%$ to $93.8 \%$ [94,95,97]. In a recent meta-analysis that included 23 CEUS studies, the pooled estimate sensitivity for the diagnosis of ductal adenocarcinoma was $89 \%$, with average specificity of $84 \%$ [99].

Cystic focal pancreatic lesions. CEUS is useful for the differential diagnosis between pseudocysts, which are completely nonenhancing during CEUS, as opposed to cystic tumors, where the cystic wall, as well as the septa and protrusions will enhance after the contrast bolus [88,94,100-103].

Acute pancreatitis (AP). CEUS can be used in acute pancreatitis (when the pancreas is well seen on conventional US) and UCA reveals necrotic areas as nonenhancing ones. Several studies confirmed the value of CEUS for detecting pancreatic necrosis and for predicting the severity of AP, with sensitivity ranging from $82 \%$ to $90.3 \%$ and specificity from $89 \%$ to $98.8 \%$ [95,104,105].

Recommendations:

a. CEUS is useful for the differential diagnosis between ductal adenocarcinoma vs. neuroendocrine tumors.

b. CEUS can be used for differentiating pseudocysts from cystic pancreatic tumors.

c. CEUS is useful for the diagnosis of pancreatic necrosis in acute pancreatitis.

\section{Kidney}

Kidney CEUS is a safe diagnostic method (especially in patients with renal dysfunction) and cancels the risk of nephrotoxicity due to CT contrast agents [106,107].
Differentiation of renal tumors from pseudotumours. CEUS is considered highly effective for this indication [70,108]. The enhancement pattern of pseudotumours mirrors that of the surrounding parenchyma in all phases. Any other enhancing pattern should be considered suspicious for malignancy [107,109,110].

Complex renal cysts. Cysts can present as equivocal, complex, or hyperdense and require differentiation of malignant from benign. The Bosniak classification system modified for CEUS evaluates the cystic lesions in terms of quantity, thickness and enhancement of walls and septa [111]. Benign lesions typically show no enhancement; this reliably confirms benignity with a $100 \% \mathrm{PPV}$ [112]. CEUS can identify more septa, characterize them as thicker and pick up solid components within cystic lesions at least as accurately as CT [106,107,109,112]. CEUS can demonstrate slow and low flow within lesions and allows their characterization as solid [113].

Indeterminate renal lesions. The differentiation between renal cell carcinomas (RCCs) and various benign entities, such as angiomyolipomas or oncocytomas is difficult [113], therefore CEUS alone is not recommended for the purpose of characterising solid lesions [109]. The typical enhancement pattern of solid RCCs includes a rapid "wash-in" phase, with a hyper-enhanced appearance at peak enhancement, followed by "wash-out" [107,109,110].

Perfusion deficit assessment. CEUS is an effective and reproducible method for detecting acute renal infarction, with accuracy comparable to CT. On CEUS it appears as a "wedge-shaped" area of nonperfusion; cortical necrosis appearance is similar, but with preserved hilar vascularity [70,107,108].

Renal infection. Renal abscesses demonstrate central non-enhancement in all phases. CEUS is as good as CT for diagnosing uncomplicated pyelonephritis, demonstrating focal pyelonephritis as a "wedge-shaped" or round region of hypoenhancement, best seen in the late parenchymal phase [107,114,115].

Targeted renal ablation (RFA and cryotherapy) guidance and follow-up. CEUS is recommended when performing US-guided RFA, as it can improve lesion localisation. On follow-up CEUS, the residual tumour appears as nodular or a ,crescent like” lesion, with similar enhancement characteristics as on the preablation imaging [107].

Transplant kidneys. CEUS may assess vascular dynamics to predict graft success or failure: if the allograft does not enhance or lacks cortical or regional enhancement, this may indicate an inflow or outflow problem [109]. CEUS can also improve the vessels' conspicuity, as it is not angle dependent like Doppler US [106,107]. 
Recommendations:

a. CEUS can discriminate between cystic and solid kidney lesions.

b. CEUS is very accurate in the diagnosis of acute vascular disturbances.

c. Kidney abscesses can be accurately diagnosed by CEUS.

\section{Testis diseases}

Inflammations and abscesses. Orchitis and orchiepididymitis are acute diseases, showing testicular pain and swelling [116]. US reveals hypoechoic lesions, hyperemic on Doppler examination $[117,118]$. In abscesses, CEUS reveals a lesion with intense, peripheral contrast uptake, with a nonenhancing center [119].

Acute vascular diseases. The typical US alteration in acute testicular torsion is hypoechogenicity of the testicle and a lack of vascular signal on Doppler, which may still be present if the torsion is incomplete. CEUS may reveal a different uptake of the UCA within the affected testicle as compared with the healthy one [120,121]. Segmental infarction is usually hypoechoic or with mixed echogenicity, well defined, feather or round shaped, with decreased or absent vascularity, raising differential diagnosis issues with a hypovascular tumor [122]. CEUS shows lack of contrast enhancement within the lesion [117,122].

Trauma. Hematoma (hematocele) - in early traumatic injury, the US appearance is echoic and, in time it becomes anechoic, with or without septa, with no Doppler signal and with no enhancement on CEUS [123-125]. Testicular fracture - CEUS detects the viable testicular tissue and its delimitation as well as the fracture line $[125,126]$. Testicular rupture - US is able to identify testicular rupture with $100 \%$ sensitivity and $65 \%$ specificity [127]. CEUS can identify intratesticular fluid collections, their extent and ruptures of the albuginea [128].

Tumors. CEUS is useful in the discrimination between cysts and parenchimal tumors (no enhancement in cystic lesions), but there is no specific pattern in relation to the tumor type.

\section{Recommendations:}

a. CEUS is useful for evaluating testicular torsion and the complications of acute orchitis/epididymitis.

b. CEUS can be used in the assessment of testicular trauma, to identify the lesions' extent, possible hematomas and non-viable testicular tissue.

\section{Bowel}

Inflammatory bowel diseases. In Crohn's disease (CD), CEUS enables discrimination between active and inactive disease, highlighting the enhancement pattern of the bowel wall microcirculation. In qualitative studies, active disease is characterized by hyperenhancement. In quantitative analysis, linear enhanced pattern in the entire intestinal wall indicates active disease, while enhancement in the submucosa indicates inactive disease $[129,130]$. CEUS enables the diagnosis of CD complications - discrimination between inflammatory and fibrotic intestinal strictures - by identifying hyperenhancement in inflammatory stenosis and hypoenhancement in fibrotic stenosis $[129,131]$. In the case of stenosis, combining CEUS with oral fluid enables the assessment of stenosis severity $[129,132]$. Also, CEUS is useful for the differential diagnosis between inflammatory pseudo-tumors (intense enhancement within the lesion and in the peripheral tissue) and abscesses (peripheral enhancement without enhancement within the lesion) [129,131,133]. CEUS can be used to monitor therapeutic response of inflammation and wall neovascularity in CD [130,133,134].

The usefulness and practical applicability of CEUS in ulcerative colitis (UC) is less defined so far. The main benefits of CEUS in UC is demonstrating the selectivity of parietal layer involvement [129], establishing the disease activity (hyper-enhancement in the thickened submucosal layer of the colon) $[131,135]$ and monitoring the treatment response [134].

CEUS is also useful for the diagnosis of acute bowel ischemia and necrosis (irrespective of the cause), suggested by the lack of, or diminished enhancement of the bowel wall [131,136].

CEUS can be used in complicated acute diverticulitis to differentiate between phlegmonous and abscessed areas, or to guide percutaneous drainage of a peridiverticular collection [129,137,138].

\section{Recommendations:}

a. In inflammatory bowel disease (especially Crohn's disease), CEUS is useful for establishing disease activity and for the assessment of complications;

b. In complicated acute diverticulitis, CEUS can be used to differentiate between the phlegmon and abscess and to guide percutaneous drainage.

\section{CEUS in trauma}

CEUS can provide significant diagnostic aid in blunt abdominal trauma (BAT). Approach to a trauma patient implies a timely and appropriate choice of the imaging method, depending on the impact severity and cardiovascular status. Thus, a high-energy multitrauma case will call for a rapid baseline conventional US scan, through the well-established Focused Assessment with Sonography in Trauma (FAST) protocol [139], which is highly 
sensitive for detecting free abdominal fluid. The second step is establishing the presence and extent of organ lesions. Although CECT is the gold-standard method for evaluating solid organ lesions, CEUS has proven to be superior in some trauma-related settings. This is the case of hypovascular areas with slow blood flow at the edge of lacerations, or in contusion areas, where blood flow is hindered by the presence of edema [140]. CEUS has a high sensitivity for detecting post-traumatic lesions of the liver, spleen and kidney, given the rich vascularity of these organs. Trauma-related organ lesions recognizable through CEUS are non-enhancing defects, as in haematoma and lacerations, and also vascular complications, such as active bleeding, arterial-venous fistulas or pseudoaneurysms [141]. Parenchymal enhancement and duration of each vascular phase is different, depending on the vascular particularity of each organ. Thus, CEUS examination should be performed in the following sequence: right kidney - left kidney - liver - spleen [142]. Main limitations of CEUS in the assessment of trauma patients reside in the examination time, lack of a complete abdominal survey and the poor ability to evaluate injuries of the urinary tract (because UCA are strictly intravascular) [142].

\section{Recommendations:}

a. CEUS has good diagnostic accuracy in identifying traumatic lesions of the liver, spleen and kidney.

b. The most suitable candidates for CEUS examination in trauma are hemodynamically stable patients, who have suffered a low-energy BAT, pediatric patients and fertile women (avoiding radiation).

\section{Pediatric population}

Use of CEUS in pediatric applications has obvious benefits compared to alternative imaging modalities (CECT). Children should be assessed using a friendly imaging method, without any ionizing radiation. Despite its advantages and performance, currently pediatric CEUS is principally used as an "off-label" application in Europe. In 2016, the Food and Drug Administration (FDA) has authorized the use of sulfur hexafluoride lipid type A microspheres (LUMASON ${ }^{\mathrm{TM}}$ ) in the United States of America, for both adult and pediatric liver applications [143]. In 2017, EFSUMB assessed the current status of CEUS applications in children [144].

The main indication of CEUS in pediatrics is the characterization of FLL. The enhancement patterns of FLL in children are similar to those seen in adults. The largest series of FLL evaluated with CEUS in children showed $98 \%$ specificity for the diagnosis of benign FLL, based on the enhancement patterns and the absence of "wash-out" during portal venous phases $[145,146]$.

In trauma, CEUS has shown to be a reliable tool in the diagnosis and follow-up of liver, spleen and renal injuries in pediatric patients $[147,148]$.

Contrast-enhanced voiding urosonography is a wellestablished application of pediatric CEUS. The method is highly sensitive in the detection and grading of vesicoureteral reflux and, in many centres, it has replaced the traditional voiding cystourethrogram $[149,150]$.

There are only few data available regarding the assessment of focal lesions of the spleen, kidney, lung, or renal transplants in children, so CEUS has limited application in these fields.

\section{Recommendation:}

CEUS is an effective "off label" investigation in children, especially for FLLs characterization, for identifying parenchymal injuries following BAT and for contrastenhanced voiding urosonography.

\section{Intracavitary applications}

Intracavitary use of UCA (IC-CEUS) is an "off-label" extravascular application. It can be used either as UCA injection into physiological cavities, or as an injection into non-physiological cavities and fistulas [70,151,152]. The UCA dose used for IC-CEUS is $0.1-1 \mathrm{ml}$ Sono-Vue diluted in $0.9 \%$ saline [70]. A higher dose of UCA (up to $1-2 \mathrm{ml}$ ) is required for high frequency US probes or to demonstrate a connection between two cavities, as well as the anatomy of fistulas [70,151].

\section{Injection into physiological cavities}

Peritoneo-pleural communication. In patients with hydrothorax and ascites, the intraperitoneal administration of 1.2-4.8 $\mathrm{ml}$ Sono-Vue demonstrates the passage of UCA into the pleural cavity [153].

Bile ducts. The intrabiliary administration improves visualization of drainage catheters and assesses the level and severity of obstruction, with comparable accuracy to percutaneous transhepatic colangiography $[154,155]$.

Pyelocalycial system. With IC-CEUS, it is possible to confirm the correct insertion of the needle or catheter and locate the obstruction. Complications such as catheter dislodgement and urine leakage may be easily diagnosed [156].

Voiding US for vesicoureteral reflux (this topic is described in pediatrics).

Imaging of tubal patency - hystero-salpingo contrastsonography is accurate in determining tubal patency and evaluating the uterine cavity, suggesting it could supplant hystero-salpingography as the first-line diagnostic test in an infertility workup $[157,158]$. 
Other intracavitary applications. The oral administration of UCA can reveal space-occupying gastric lesions such as tumoral masses or gastric balloons; gastroesophageal reflux or gastric empting troubles; cholecysto-duodenal fistulas; spontaneous perforations, constrictions of the gastric outlet tract; and patency of endoscopically inserted stents [70,151].

\section{Contrast injection into non-physiological cavities and fistulas}

Abscesses. Administration of UCA into the drainage catheters improves the assessment of location characteristics (correct position, mishandled or dislocated) and of complications of drained fluid collections $[152,159]$. The communication with the biliary tree is depicted with high sensitivity in both intrahepatic abscesses and perihepatic collections [160].

Fistulas. An accurate preoperative assessment of perianal fistula tract is mandatory to decrease postoperative complications and risk of recurrence $[161,162]$. The injection of UCA (hydrogen peroxide or SonoVue) into the fistula allows a better visualization of its track and of the internal opening [151]. The diagnostic sensitivity is higher as compared to normal US, in both simple (9596\%) and complex fistulas (92.3\%) [162]. Rectovaginal fistulas can also be evaluated via a transvaginal approach [163], and vesicoenteral fistulas via a transabdominal approach $[163,164]$.

\section{Recommendations:}

a. IC-CEUS is a useful technique in optimizing biliary interventions, possibly avoiding the use of $X$ rays in selected cases.

b. In percutaneous drainage, the use of IC-CEUS increases the efficacy, decreases the complications rate and may select additional therapy.

\section{Contrast harmonic imaging endoscopic ultrasound}

Endoscopic ultrasound (EUS) is a high resolution technique that allows a detailed examination of the gastrointestinal tract (GI) wall and surrounding structures, including the pancreas. Contrast harmonic imaging EUS (CHI-EUS) uses a low mechanical index (MI) mode, in order to better characterise focal pancreatic masses, improve staging for pancreatico-biliary and GI tract cancers, and possibly guide therapeutic EUS interventions, including EUS-fine needle aspiration (EUS-FNA) $[165,166]$

CHI-EUS can be used for the differential diagnosis of hypoenhancing pancreatic adenocarcinoma as opposed to other iso- or hyperenhancing solid pancreatic lesions (neuroendocrine tumors, pancreatic metastases, chronic pseudo-tumoral pancreatitis, etc.). It is useful for the differential diagnosis of benign and malignant pancreatic focal lesions, where the concomitant use of CHI-EUS and EUS-FNA has an additive value to increase the overall accuracy by decreasing false negative results of both techniques [167]. Two recent meta-analyses reported high sensitivity and specificity of CHI-EUS for the differential diagnosis of pancreatic adenocarcinoma $[99,168]$.

Both qualitative and quantitative (time intensity curve analysis) CHI-EUS can be performed during pancreas examinations. Pancreatic ductal adenocarcinoma typically shows heterogeneous hypoenhancement, whilst other solid masses exhibit iso- or hyperenhancement [169]. Pancreatic neuroendocrine tumors typically show hyperenhancement followed by "wash-out", filling defects being predictive of malignancy [170]. CHI-EUS can be used complementary to EUS-FNA in order to increase the diagnostic yield and accuracy through the guidance of the needle during real-time CEUS [171].

Pseudotumoral chronic pancreatitis shows iso- or hyperenhancement [172]. Likewise, autoimmune pancreatitis shows hyper-enhancement during CHI-EUS and can be differentiated from pancreatic adenocarcinoma [173].

CHI-EUS has been used in cystic pancreatic lesions, due to the increased resolution and ability to image the wall, septa and mural nodules [174]. Thus, the differentiation between mural nodules as opposed to debris and intra-cystic mucus can be easily made [175]. Consequently, pancreatic pseudocysts can be differentiated from neoplastic cystic tumors (serous cystadenomas, mucinous cystic neoplasms and intrapapillary mucinous neoplasms). However, the differential diagnosis between serous cystadenoma and mucinous neoplastic lesions cannot be based on CHI-EUS only.

Other applications of CHI-EUS include the evaluation of malignant gallbladder polyps [176], as well as assessment of GI tract wall lesions, including malignant GIST lesions as compared to other benign submucosal tumors [177].

\section{Recommendations:}

a. CHI-EUS is useful for the differentiation of focal pancreatic masses, especially hypoenhancing pancreatic adenocarcinoma as opposed to other isoor hyperenhancing solid pancreatic lesions.

b. CHI-EUS is useful for the differential diagnosis of cystic pancreatic masses, due to the enhanced visualisation of the wall, septa and mural nodules, being able to differentiate pseudocysts and cystic neoplastic lesions.

\section{Other CEUS applications}

Vascular applications. CEUS can accurately visualize and evaluate the micro-vascularization - through Dy- 
namic Contrast Enhanced Ultrasound (DCE-US) - [70], and also the medium and large vessels [178]. CEUS can confidently be used to assess abdominal aortic aneurysm and its complications [179] and to characterize atherosclerotic plaques, especially in the carotid artery [180]. Arteriovenous fistulas can also be assessed by CEUS [181].

CEUS is able to evaluate the veins patency, to assess thrombus extension [181] and can differentiate between benign or malignant portal vein thrombosis $[182,183]$. In liver transplantation, CEUS can depict the vascular patency, and also the ischemic areas or hemorrhage within the liver $[5,184,185]$.

Lung applications. The lung has a dual vascularization consisting of pulmonary artery and systemic bronchial artery supply [186]. An arrival time in a consolidation area of less than 8-10 seconds ("early arterial enhancement") significates pulmonary arterial supply, while a delayed arrival time, over 10 seconds ("late arterial enhancement") indicates supply by the bronchial arteries [186,187]. In pneumonia there is early and intense arterial enhancement $(<10 \mathrm{sec})$; "wash-out" is mild and late $[186,188]$. In embolic pulmonary infarcts, the CEUS enhancement is minimal or absent in $80 \%$ of cases $[186,189]$. In atelectasis, similar to pneumonia, the enhancement is early and intense $(<10 \mathrm{~s})$, followed by a plateau $[186,190]$. In pulmonary tumors, due to an arterial supply from the bronchial system, enhancement is usually late $[186,187]$. Unenhancing areas such as abscesses in pneumonia, or a hypoenhanced area representing a central tumor, in obstructive atelectasis can be easily detected by CEUS [186]. Using CEUS, either before or as a real time guiding tool during biopsy, it is possible to target a central lung tumor in an atelectatic mass, or to avoid necrosis in large lung and mediastinal lesions [191,192].

UCA can also play a role in delivering drugs or biological vectors [193].

\section{Recommendations:}

Other applications of UCA are: evaluation of microvascularization through Dynamic Contrast Enhanced Ultrasound, evaluation of abdominal aortic aneurysm and its complications, of venous thrombosis and of vessels patency and differential diagnosis in consolidation lung diseases.

\section{Acknowledgements:}

Part of the research published in this paper was made with support from the grant awarded by the "Victor Babeş" University of Medicine and Pharmacy Timisoara, in PROGRAMUL III - C2 - PCFI - 2015/2016.

\section{References}

1. Lanka B, Jang HJ, Kim TK, Burns PN, Wilson SR. Impact of contrast-enhanced ultrasonography in a tertiary clinical practice. J Ultrasound Med 2007;26:1703-1714.

2. Strobel D, Seitz K, Blank W, et al. Contrast-enhanced ultrasound for the characterization of focal liver lesions - diagnostic accuracy in clinical practice (DEGUM multicenter trial). Ultraschall Med 2008;29:499-505.

3. Guang Y, Xie L, Ding H, Cai A, Huang Y. Diagnosis value of focal liver lesions with SonoVue ${ }^{\circledR}$-enhanced ultrasound compared with contrast-enhanced computed tomography and contrast-enhanced MRI: a meta-analysis. J Cancer Res Clin Oncol 2011;137:1595-1605.

4. Greis C. Technology overview: SonoVue (Bracco, Milan). Eur Radiol 2004;14 Suppl 8:P11-P15.

5. Claudon M, Dietrich CF, Choi BI, et al. Guidelines and good clinical practice recommendations for Contrast Enhanced Ultrasound (CEUS) in the liver - update 2012: a WFUMB-EFSUMB initiative in cooperation with representatives of AFSUMB, AIUM, ASUM, FLAUS and ICUS. Ultraschall Med 2013;34:11-29.

6. Claudon M, Cosgrove D, Albrecht T, et al. Guidelines and good clinical practice recommendations for contrast enhanced ultrasound (CEUS) - update 2008. Ultraschall Med 2008;29:28-44.

7. Minimum training requirements for the practice of Medical Ultrasound in Europe. Ultraschall Med 2010;31:426-427.

8. Piscaglia F, Bolondi L; Italian Society for Ultrasound in Medicine and Biology (SIUMB) Study Group on Ultrasound Contrast Agents. The safety of Sonovue in abdominal applications: retrospective analysis of 23188 investigations. Ultrasound Med Biol 2006;32:1369-1375.

9. Correas JM, Low G, Needleman L, et al. Contrast enhanced ultrasound in the detection of liver metastases: a prospective multi-centre dose testing study using a perfluorobutane microbubble contrast agent (NC100100). Eur Radiol 2011;21:1739-1746.

10. Friedrich-Rust M, Klopffleisch T, Nierhoff J, et al. Contrast-Enhanced Ultrasound for the differentiation of benign and malignant focal liver lesions: a meta-analysis. Liver Int 2013;33:739-755.

11. Dietrich CF, Maddalena ME, Cui XW, Schreiber-Dietrich D, Ignee A. Liver tumor characterization - review of the literature. Ultraschall Med 2012;33 Suppl 1:S3-S10.

12. Trillaud H, Bruel JM, Valette PJ, et al. Characterization of focal liver lesions with SonoVue ${ }^{\circledR}$-enhanced sonography: International multicenter-study in comparison to $\mathrm{CT}$ and MRI. World J Gastroenterol 2009;15:3748-3756.

13. Sporea I, Badea R, Popescu A, et al. Contrast-enhanced ultrasound (CEUS) for the evaluation of focal liver lesions - a prospective multicenter study of its usefulness in clinical practice. Ultraschall Med 2014;35:259-266.

14. Semelka RC, Sofka CM. Hepatic hemangiomas. Magn Reson Imaging Clin N Am 1997;5:241-253.

15. McArdle CR. Ultrasonic appearances of a hepatic hemangioma. J Clin Ultrasound 1978;6:124. 
16. Sirli R, Sporea I, Săndulescu DL. et al. Contrast enhanced ultrasound for the diagnosis of liver hemangiomas - results of a Romanian multicentre study. Med Ultrason 2015; 17:444-450.

17. Fang L, Zhu Z, Huang B, et al. A comparative study of contrast enhanced ultrasound and contrast enhanced magnetic resonance imaging for the detection and characterization of hepatic hemangiomas. Biosci Trends 2015;9:104-110.

18. Seitz K, Strobel D, Bernatik T, et al. Contrast-Enhanced Ultrasound (CEUS) for the characterization of focal liver lesions - prospective comparison in clinical practice: CEUS vs. CT (DEGUM multicenter trial). Parts of this Manuscript were presented at the Ultrasound Dreiländertreffen 2008, Davos. Ultraschall Med 2009;30:383-389.

19. Fukukura Y, Nakashima O, Kusaba A, Kage M, Kojiro M. Angioarchitecture and blood circulation in focal nodular hyperplasia of the liver. J Hepatol 1998;29:470-475.

20. Weskott HP. The role of CEUS in identifying and characterizing focal liver lesions. In: Bolondi L (eds). Advances in Diagnostic Imaging. Springer, 2006;17-45.

21. Sporea I, Sirli R, Sandulescu DL, et al. Contrast-Enhanced Ultrasound Performance in the Evaluation of Focal Nodular Hyperplasia in a Multicenter Study. Ultrasound Med Biol 2017;43(Suppl 1):s49.

22. Tranquart F, Le Gouge A, Correas JM, et al. Role of contrastenhanced ultrasound in the blinded assessment of focal liver lesions in comparison with MDCT and CEMRI: Results from a multicentre clinical trial. EJC Suppl 2008;6:9-15.

23. Roche V, Pigneur F, Tselikas L, et al. Differentiation of focal nodular hyperplasia from hepatocellular adenomas with low-mechanical-index contrast-enhanced sonography (CEUS): effect of size on diagnostic confidence. Eur Radiol 2015;25:186-195.

24. Gonzalez A, Canga F, Cardenas F, et al. An unusual case of hepatic adenoma in a male. J Clin Gastroenterol 1994;19:179-181.

25. Gaiani S, Volpe L, Piscaglia F, Bolondi L. Vascularity of liver tumours and recent advances in Doppler ultrasound. J Hepatol 2001;34:474-482.

26. Dietrich CF, Lee JH, Gottschalk R, et al. Hepatic and portal flow pattern in correlation with intrahepatic fat deposition and liver histology in patients with chronic hepatitis C. AJR Am J Roentgenol 1998:171:437-443.

27. Liu LP, Dong BW, Yu XL, Zhang DK, Kang CS, Zhao XH. Evaluation of focal fatty infiltration of the liver using color Doppler and contrast-enhanced sonography. J Clin Ultrasound 2008;36:560-566.

28. Janica J, Ustymowicz A, Lukasiewicz A, et al. Comparison of contrast-enhanced ultrasonography with grey-scale ultrasonography and contrast-enhanced computed tomography in diagnosing focal fatty liver infiltrations and focal fatty sparing. Adv Med Sci 2013;58:408-418.

29. Hui JY, Yang MK, Cho DH, et al. Pyogenic liver abscesses caused by Klebsiella pneumoniae: US appearance and aspiration findings. Radiology 2007;242:769-776.

30. Kishina M, Koda M, Tokunaga S, et al. Usefulness of contrast-enhanced ultrasound with Sonazoid for evaluating liver abscess in comparison with conventional B-mode ultrasound. Hepatol Res 2015;45:337-342.

31. Liu GJ, Lu MD, Xie XY, et al. Real-time contrast-enhanced ultrasound imaging of infected focal liver lesions. J Ultrasound Med 2008;27:657-666.

32. Popescu A, Sporea I, Şirli R, et al. Does Contrast Enhanced Ultrasound improve the management of liver abscesses? A single centre experience. Med Ultrason 2015;17:451-455.

33. Ignee A, Schuessler G, Cui XW, Dietrich CF. Intracavitary contrast medium ultrasound - different applications, a review of the literature ad future prospects. Ultraschall Med 2013;34:504-525.

34. Ignee A, Jenssen C, Cui XW, Schuessler G, Dietrich CF. Intracavitary contrast-enhanced ultrasound in abscess drainage - feasibility and clinical value. Scand J Gastroenterol 2016;51:41-47.

35. Quaia E, Calliada F, Bertolotto M, et al. Characterization of focal liver lesions with contrast-specific US modes and a sulfur hexafluoride-filled microbubble contrast agent: diagnostic performance and confidence. Radiology 2004;232:420-430.

36. Jang HJ, Kim TK, Wilson SR. Imaging of malignant liver masses: characterization and detection. Ultrasound Q 2006;22:19-29.

37. D'Onofrio M, Mansueto G, Falconi M, Procacci C. Neuroendocrine pancreatic tumor: value of contrast enhanced ultrasonography. Abdom Imaging 2004;29:246-258.

38. Malagò R, D’Onofrio M, Zamboni GA, et al. Contrast-enhanced sonography of nonfunctioning pancreatic neuroendocrine tumors. AJR Am J Roentgenol 2009;192:424-430.

39. Dietrich CF, Kratzer W, Strobe D, et al. Assessment of metastatic liver disease in patients with primary extrahepatic tumors by contrast-enhanced sonography versus CT and MRI. World J Gastroenterol 2006;12:1699-1705.

40. Hohmann J, Muller A, Skrok J, et al. Detection of hepatocellular carcinoma and liver metastases with BR14: a multicenter phase IIA study. Ultrasound Med Biol 2012;38:377382.

41. Quaia E, D’Onofrio M, Palumbo A, Rossi S, Bruni S, Cova M. Comparison of contrast-enhanced ultrasonography versus baseline ultrasound and contrast-enhanced computed tomography in metastatic disease of the liver: diagnostic performance and confidence. Eur Radiol 2006;16:15991609.

42. Bruix J, Sherman M; American Association for the Study of Liver Diseases. Management of hepatocellular carcinoma: an update. Hepatology 2011;53:1020-1022.

43. International Consensus Group for Hepatocellular Neoplasia. Pathologic diagnosis of early hepatocellular carcinoma: a report of the international consensus group for hepatocellular neoplasia. Hepatology 2009;49:658-664.

44. Matsui O. Detection and characterization of hepatocellular carcinoma by imaging. Clin Gastroenterol Hepatol 2005;3:S136-S140.

45. Martie A, Sporea I, Sirli R, Popescu A, Danila M. How often hepatocellular carcinoma has a typical pattern in contrast enhanced ultrasound? Maedica (Buchar) 2012;7:236-240. 
46. Wilson SR, Jang HJ, Kim TK, Iijima H, Kamiyama N, Burns PN. Real-time temporal maximum-intensity-projection imaging of hepatic lesions with contrast-enhanced sonography. AJR Am J Roentgenol 2008;190:691-695.

47. Boozari B, Soudah B, Rifai K, et al. Grading of hypervascular hepatocellular carcinoma using late phase of contrast enhanced sonography - a prospective study. Dig Liver Dis 2011;43:484-490.

48. Liu GJ, Xu HX, Lu MD, et al. Correlation between enhancement pattern of hepatocellular carcinoma on real-time contrast-enhanced ultrasound and tumour cellular differentiation on histopathology. $\mathrm{Br} \mathrm{J}$ Radiol 2007;80:321-330.

49. Bhayana D, Kim TK, Jang HJ, Burns PN, Wilson SR. Hypervascular liver masses on contrast-enhanced ultrasound: the importance of washout. AJR Am J Roentgenol 2010;194:977-983.

50. Bolondi L, Gaiani S, Celli N, et al. Characterization of small nodules in cirrhosis by assessment of vascularity: the problem of hypovascular hepatocellular carcinoma. Hepatology 2005;42:27-34.

51. Jang HJ, Kim TK, Wilson SR. Small nodules $(1-2 \mathrm{~cm})$ in liver cirrhosis: characterization with contrast-enhanced ultrasound. Eur J Radiol 2009;72:418-424.

52. Hanna RF, Miloushev VZ, Tang A, et al. Comparative 13year meta-analysis of the sensitivity and positive predictive value of ultrasound, CT, and MRI for detecting hepatocellular carcinoma. Abdom Radiol (NY) 2016;41:71-90.

53. Galassi M, Iavarone M, Rossi S, et al. Patterns of appearance and risk of misdiagnosis of intrahepatic cholangiocarcinoma in cirrhosis at contrast enhanced ultrasound. Liver Int 2013;33:771-779.

54. Li R, Zhang X, Ma KS, et al. Dynamic enhancing vascular pattern of intrahepatic peripheral cholangiocarcinoma on contrast-enhanced ultrasound: the influence of chronic hepatitis and cirrhosis. Abdom Imaging 2013;38:112-119.

55. Bohle W, Clemens PU, Heubach T, Zoller WG. Contrastenhanced ultrasound (CEUS) for differentiating between hepatocellular and cholangiocellular carcinoma. Ultraschall Med 2012;33:E191-E195.

56. Bloom CM, Langer B, Wilson SR. Role of US in the detection, characterization, and staging of cholangiocarcinoma. Radiographics 1999;19:1199-1218.

57. Li C, Wang W, Ding H, et al. Value of contrast-enhanced sonography in the diagnosis of peripheral intrahepatic cholangiocarcinoma. J Clin Ultrasound 2011;39:447-453.

58. $\mathrm{Xu} \mathrm{HX,} \mathrm{Lu} \mathrm{MD,} \mathrm{Liu} \mathrm{GJ,} \mathrm{et} \mathrm{al.} \mathrm{Imaging} \mathrm{of} \mathrm{peripheral}$ cholangiocarcinoma with low-mechanical index contrastenhanced sonography and SonoVue: initial experience. J Ultrasound Med 2006;25:23-33.

59. Chen LD, Xu HX, Xie XY, et al. Intrahepatic cholangiocarcinoma and hepatocellular carcinoma: differential diagnosis with contrast-enhanced ultrasound. Eur Radiol 2010;20:743-753.

60. Piscaglia F, Cucchetti A, Dietrich CF, Salvatore V. Towards new tools for refined management of patients with advanced hepatocellular carcinoma under systemic ther- apy: some enthusiasm with a word of caution. J Hepatol 2013;59:924-925.

61. Asayama Y, Yoshimitsu K, Irie H, et al. Delayed phase dynamic CT enhancement as a prognostic factor for massforming intrahepatic cholangiocarcinoma. Radiology 2006;238:150-155.

62. Lacomis JM, Baron RL, Oliver JH 3rd, Nalesnik MA, Federle MP. Cholangiocarcinoma: delayed CT contrast enhancement patterns. Radiology 1997;203:98-104.

63. Barreiros AP, Piscaglia F, Dietrich CF. Contrast enhanced ultrasound for the diagnosis of hepatocellular carcinoma (HCC): comments on AASLD guidelines. J Hepatol 2012;57:930-932.

64. Vilana R, Forner A, Bianchi L, et al. Intrahepatic peripheral cholangiocarcinoma in cirrhosis patients may display a vascular pattern similar to hepatocellular carcinoma on contrast-enhanced ultrasound. Hepatology 2010;51:20202029.

65. Chen LD, Xu HX, Xie XY, et al. Enhancement patterns of intrahepatic cholangiocarcinoma: comparison between contrast-enhanced ultrasound and contrast-enhanced CT. Br J Radiol 2008;81:881-889.

66. Wildner D, Bernatik T, Greis C, Seitz K, Neurath MF, Strobel D. CEUS in hepatocellular carcinoma and intrahepatic cholangiocellular carcinoma in 320 patients - early or late washout matters: a subanalysis of the DEGUM multicenter trial. Ultraschall Med 2015;36:132-139.

67. Li R, Yuan MX, Ma KS, et al. Detailed analysis of temporal features on contrast enhanced ultrasound may help differentiate intrahepatic cholangiocarcinoma from hepatocellular carcinoma in cirrhosis. PLoS One 2014;9:e98612.

68. Han J, Liu Y, Han F, et al. The degree of contrast washout on contrast-enhanced ultrasound in distinguishing intrahepatic cholangiocarcinoma from hepatocellular carcinoma. Ultrasound Med Biol 2015;41:3088-3095.

69. Stang A, Keles H, Hentschke S, et al. Differentiation of benign from malignant focal splenic lesions using sulfur hexafluoride-filled microbubble contrast-enhanced pulse-inversion sonography. AJR Am J Roentgenol 2009;193:709-721.

70. Piscaglia F, Nolsøe C, Dietrich CF, et al. The EFSUMB Guidelines and Recommendations on the Clinical Practice of Contrast Enhanced Ultrasound (CEUS): update 2011 on non-hepatic applications. Ultraschall Med 2012;33:33-59.

71. Gorg C, Graef C, Bert T. Contrast-enhanced sonography for differential diagnosis of an inhomogeneous spleen of unknown cause in patients with pain in the left upper quadrant. J Ultrasound Med 2006;25:729-734.

72. Stang A, Keles H, Hentschke S, et al. Incidentally detected splenic lesions in ultrasound: does contrast-enhanced ultrasonography improve the differentiation of benign hemangioma/hamartoma from malignant lesions? Ultraschall Med 2011;32:582-592.

73. Yu X, Yu J, Liang P, Liu F. Real-time contrast-enhanced ultrasound in diagnosing of focal spleen lesions. Eur J Radiol 2012;81:430-436.

74. von Herbay A, Barreiros AP, Ignee A, et al. Contrast-enhanced ultrasonography with SonoVue: differentiation be- 
tween benign and malignant lesions of the spleen. J Ultrasound Med 2009;28:421-434.

75. Neesse A, Huth J, Kunsch S, et al. Contrast-enhanced ultrasound pattern of splenic metastases - a retrospective study in 32 patients. Ultraschall Med 2010;31:264-269.

76. Goerg C, Schwerk WB, Goerg K. Sonography of focal lesions of the spleen. AJR Am J Roentgenol 1991;156:949-953.

77. Robertson F, Leander P, Ekberg O. Radiology of the spleen. Eur Radiol 2001;11:80-89.

78. Catalano O, Sandomenico F, Matarazzo I, Siani A. Contrast-enhanced sonography of the spleen. AJR Am J Roentgenol 2005; 184:1150-1156.

79. Popescu A, Sporea I, Sirli R, Danila M, Nicolita D, Martie A. The role of contrast-enhanced ultrasonography with second generation contrast agents in the evaluation of focal splenic lesions. Med Ultrason 2009;11:61-65.

80. Chiorean L, Zdrenghea M, Badea R. Ultrasonography of the spleen. Pictorial essay. Med Ultrason 2014;16:48-59.

81. Bertolotto M, Quaia E, Zappetti R, Cester G, Turoldo A. Differential diagnosis between splenic nodules and peritoneal metastases with contrast-enhanced ultrasound based on signal-intensity characteristics during the late phase. Radiol Med 2009;114:42-51.

82. Gorg C, Bert T. Second-generation sonographic contrast agent for differential diagnosis of perisplenic lesions. AJR Am J Roentgenol 2006;186:621-626.

83. De Robertis R, D’Onofrio M, Manfrin E, Dal Bo C, Pozzi Mucelli R. A Rare Case of Pancreatic Head Splenosis Diagnosed by Contrast-Enhanced Ultrasound. Ultraschall Med 2014;35:72-74

84. Rogers P, Williams MP, Fernando R, Freeman S. Pancreatic splenosis demonstrated by contrast-enhanced sonography. J Clin Ultrasound 2011;39:348-350.

85. Ota $\mathrm{T}$, Ono S. Intrapancreatic accessory spleen: diagnosis using contrast enhanced ultrasound. Br J Radiol 2004;77:148-149.

86. Tafuto S, Catalano O, Barba G, et al. Real-time contrastenhanced specific ultrasound in staging and follow-up of splenic lymphomas. Front Biosci 2006;11:2224-2229.

87. Thorelius L. Usefulness of contrast-enhanced ultrasound in the characterization of pancreatic and renal masses. In: Albrecht T, Thorelius L, Solbiati L, Cova L, Frauscher F (eds). Contrast-Enhanced Ultrasound in Clinical Practice: Liver, Prostate, Pancreas, Kidney and Lymph Nodes. Milan, Springer, 2005:23-35.

88. D’Onofrio M, Martone E, Malagò R, et al. Contrast-enhanced ultrasonography of the pancreas. JOP 2007;8:71-76.

89. Kersting S, Konopke R, Kersting F, et al. Quantitative perfusion analysis of transabdominal contrast-enhanced ultrasonography of pancreatic masses and carcinomas. Gastroenterology 2009;137:1903-1911.

90. Numata K, Ozawa Y, Kobayashi N, et al. Contrast-enhanced sonography of pancreatic carcinoma: correlations with pathological findings. J Gastroenterol 2005;40:631-640.

91. Kitano M, Kudo M, Maekawa K, et al. Dynamic imaging of pancreatic diseases by contrast enhanced coded phase inversion harmonic ultrasonography. Gut 2004;53:854-859.
92. Faccioli N, D’Onofrio M, Malago R, et al. Resectable pancreatic adenocarcinoma: depiction of tumoral margins at contrast-enhanced ultrasonography. Pancreas 2008;37:265-268.

93. Grossjohann HS, Rappeport ED, Jensen C, et al. Usefulness of contrast-enhanced transabdominal ultrasound for tumor classification and tumor staging in the pancreatic head. Scand J Gastroenterol 2010;45:917-924.

94. D’Onofrio M, Barbi E, Dietrich CF, et al. Pancreatic multicenter ultrasound study (PAMUS). Eur J Radiol 2012;81:630-638.

95. Ardelean M, Şirli R, Sporea I, et al. Contrast enhanced ultrasound in the pathology of the pancreas - a monocentric experience. Med Ultrason 2014;16:325-331.

96. D’Onofrio M, Gallotti A, Principe F, Mucelli RP. Contrast enhanced ultrasound of the pancreas. World J Radiol 2010;2:97-102.

97. Dietrich CF, Braden B, Hocke M, Ott M, Ignee A. Improved characterization of solitary solid pancreatic tumours using contrast enhanced transabdominal ultrasound. J Cancer Res Clin Oncol 2008;134:635-643.

98. Ardelean M, Sirli R, Sporea I, et al. The value of contrast-enhanced ultrasound in the characterization of vascular pattern of solid pancreatic lesions. Med Ultrason 2015;17:16-21.

99. D’Onofrio M, Biagioli E, Gerardi C, et al. Diagnostic performance of contrast-enhanced ultrasound (CEUS) and contrast-enhanced endoscopic ultrasound (ECEUS) for the differentiation of pancreatic lesions: a systematic review and meta-analysis. Ultraschall Med 2014;35:515-521.

100. D’Onofrio M, Caffarri S, Zamboni G, Falconi M, Mansueto G. Contrast-enhanced ultrasonography in the characterization of pancreatic mucinous cystadenoma. J Ultrasound Med 2004;23:1125-1129.

101. D’Onofrio M, Megibow AJ, Faccioli N, et al. Comparison of contrast-enhanced sonography and MRI in displaying anatomic features of cystic pancreatic masses. AJR Am J Roentgenol 2007;189:1435-1442.

102. Itoh T, Hirooka Y, Itoh A, et al. Usefulness of contrast-enhanced transabdominal ultrasonography in the diagnosis of intraductal papillary mucinous tumors of the pancreas. Am J Gastroenterol 2005;100:144-152.

103. Rickes S, Wermke W. Differentiation of cystic pancreatic neoplasms and pseudocysts by conventional and echo-enhanced ultrasound. J Gastroenterol Hepatol 2004;19:761766.

104. Rickes S, Uhle C, Kahl S, et al. Echo enhanced ultrasound: a new valid initial imaging approach for severe acute pancreatitis. Gut 2006;55:74-78.

105. Ripolles T, Martinez MJ, Lopez E, Castello I, Delgado F. Contrast-enhanced ultrasound in the staging of acute pancreatitis. Eur Radiol 2010;20:2518-2523.

106. Putz FJ, Erlmeier A, Wiesinger I, et al. Contrast-enhanced ultrasound (CEUS) in renal imaging at an interdisciplinary ultrasound centre: Possibilities of dynamic microvascularisation and perfusion. Clin Hemorheol Microcirc 2017;66:293-302. 
107. Tenant SC, Gutteridge CM. The clinical use of contrast-enhanced ultrasound in the kidney. Ultrasound 2016;24:94103.

108. Bertolotto M, Cicero C, Catalano O, Currò F, Derchi LE. Solid Renal Tumors Isoenhancing to Kidneys on Contrast-Enhanced Sonography: Differentiation From Pseudomasses. J Ultrasound Med 2017, Jul 29. doi:10.1002/ jum.14335.

109. Barr RG, Peterson C, Hindi A. Evaluation of indeterminate renal masses with contrast-enhanced US: a diagnostic performance study. Radiology 2014;271:133-142.

110. Harvey CJ, Alsafi A, Kuzmich S, et al. Role of US contrast agents in the assessment of indeterminate solid and cystic lesions in native and transplant kidneys. Radiographics 2015;35:1419-1430.

111. Bosniak MA. The Bosniak renal cyst classification: 25 years later. Radiology 2012;262:781-785.

112. Xue LY, Lu Q, Huang BJ, et al. Contrast-enhanced ultrasonography for evaluation of cystic renal mass: in comparison to contrast-enhanced CT and conventional ultrasound. Abdom Imaging 2014;39:1274-1283.

113. Kazmierski B, Deurdulian C, Tchelepi H, Grant EG. Applications of contrast-enhanced ultrasound in the kidney. Abdom Radiol (NY). 2017 Aug 30, doi:10.1007/s00261017-1307-0.

114. Li X, Liang P, Guo M, et al. Real-time contrast-enhanced ultrasound in diagnosis of solid renal lesions. Discov Med 2013;16:15-25.

115. King KG, Gulati M, Malhi H, et al. Quantitative assessment of solid renal masses by contrast-enhanced ultrasound with time-intensity curves: how we do it. Abdom Imaging 2015;40:2461-2471.

116. Nicholson A, Rait G, Murray-Thomas T, Hughes G, Mercer $\mathrm{CH}$, Cassell J. Management of epididymo-orchitis in primary care: results from a large UK primary care database. Br J Gen Pract 2010;60:e407-e422.

117. Yusuf G, Sellars ME, Kooiman GG, Diaz-Cano S, Sidhu PS. Global testicular infarction in the presence of epididymitis clinical features, appearances on grayscale, color Doppler, and contrast-enhanced sonography, and histologic correlation. J Ultrasound Med 2013;32:175-180.

118. Cook JL, Dewbury K. The changes seen on high-resolution ultrasound in orchitis. Clin Radiol 2000;55:13-18.

119. Cokkinos DD, Antypa E, Kalogeropoulos I, et al. Contrast-enhanced ultrasound performed under urgent conditions. Indications, review of the technique, clinical examples and limitations. Insights Imaging 2013;4:185-198.

120. Moschouris H, Stamatiou K, Lampropoulou E, Kalikis D, Matsaidonis D. Imaging of the acute scrotum: is there a place for contrast-enhanced ultrasonography? Int Braz J Urol 2009;35:692-702.

121. Traubici J, Daneman A, Navarro O, Mohanta A, Garcia C. Original report. Testicular torsion in neonates and infants: sonographic features in 30 patients. AJR Am J Roentgenol 2003; 180:1143-1145.

122. Valentino M, Bertolotto M, Martino P, Barozzi L, Pavlica P. Incidentally detection of non-palpable testicular nod- ules at scrotal ultrasound: What is new? Arch Ital Urol Androl 2014;86:378-382.

123. Deurdulian C, Mittelstaedt CA, Chong WK, Fielding JR. US of acute scrotal trauma: optimal technique, imaging findings, and management. Radiographics 2007;27:357-369.

124. Yusuf GT, Sidhu PS. A review of ultrasound imaging in scrotal emergencies. J Ultrasound 2013;16:171-178.

125. Valentino M, Bertolotto M, Derchi L, et al. Role of contrast enhanced ultrasound in acute scrotal diseases. Eur Radiol 2011;21:1831-1840.

126. Hedayati V, Sellars ME, Sharma DM, Sidhu PS. Contrastenhanced ultrasound in testicular trauma: role in directing exploration, debridement and organ salvage. Br J Radiol 2012;85:e65-e68.

127. Guichard G, El Ammari J, Del Coro C, et al. Accuracy of ultrasonography in diagnosis of testicular rupture after blunt scrotal trauma. Urology 2008;71:52-56.

128. Lobianco R, Regine R, De Siero M, Catalano O, Caiazzo C, Ragozzino A. Contrast-enhanced sonography in blunt scrotal trauma. J Ultrasound 2011;14:188-195.

129. Badea R, Socaciu M, Ciobanu L, Hagiu C, Golea A. Contrast-enhanced ultrasonography (CEUS) for the evaluation of the inflammation of the digestive tract wall. J Gastrointestin Liver Dis 2010;19:439-444.

130. Cantisani V, Bertolotto M, Weskott HP, et al. Growing indications for CEUS: The kidney, testis, lymph nodes, thyroid, prostate, and small bowel. Eur J Radiol 2015;84:1675-1684.

131. Braden B, Ignee A, Hocke M, Palmer RM, Dietrich C. Diagnostic value and clinical utility of contrast enhanced ultrasound in intestinal diseases. Dig Liver Dis 2010;42:667-674.

132. Badea R, Ciobanu L, Gomotirceanu A, Hagiu C, Socaciu M. Contrast ultrasonography - a necessary procedure for a better characterization of digestive tract pathology. Med Ultrason 2010;12:73-80.

133. Quaia E. Contrast-enhanced ultrasound of the small bowel in Crohn's disease. Abdom Imaging 2013;38:1005-1013.

134. Socaciu M, Ciobanu L, Diaconu B, Hagiu C, Seicean A, Badea R. Non-Invasive Assessment of Inflammation and Treatment Response in Patients with Crohn's Disease and Ulcerative Colitis using Contrast-Enhanced Ultrasonography Quantification. J Gastrointestin Liver Dis 2015;24:457-465.

135. Girlich C, Schacherer D, Jung EM, Klebl F, Huber E. Comparison between quantitative assessment of bowel wall vascularization by contrast-enhanced ultrasound and results of histopathological scoring in ulcerative colitis. Int J Colorectal Dis 2012;27:193-198.

136. Roccarina D, Garcovich M, Ainora ME, et al. Diagnosis of bowel diseases: the role of imaging and ultrasonography. World J Gastroenterol 2013;19:2144-2153.

137. Ripollés T, Martínez-Pérez MJ, Paredes JM, Vizuete J, García-Martínez E, Jiménez-Restrepo DH. Contrast-enhanced ultrasound in the differentiation between phlegmon and abscess in Crohn's disease and other abdominal conditions. Eur J Radiol 2013;82:e525-e531. 
138. Schlottmann K, Kratzer W, Schölmerich J. Doppler ultrasound and intravenous contrast agents in gastrointestinal tract disorders: current role and future implications. Eur J Gastroenterol Hepatol 2005; 17:263-275.

139. Stengel D, Rademacher G, Ekkernkamp A, Güthoff C, Mutze S. Emergency ultrasound-based algorithms for diagnosing blunt abdominal trauma. Cochrane Database Syst Rev 2015;9:CD004446.

140. Șirli R, Sporea I, Popescu A, Dănilă M. Usefulness of Contrast Enhanced Ultrasound for the evaluation of blunt abdominal trauma. Med Ultrason 2009;11:25-30.

141. Pinto F, Valentino M, Romanini L, Basilico R, Miele V. The role of CEUS in the assessment of haemodynamically stable patients with blunt abdominal trauma. Radiol Med 2015;120:3-11.

142. Miele V, Piccolo CL, Galluzzo M, Ianniello S, Sessa B, Trinci M. Contrast-enhanced ultrasound (CEUS) in blunt abdominal trauma. Br J Radiol 2016;89:20150823.

143. U.S. Food \& Drug Administration. Novel Drug Approvals for 2016. Available at: https://www.fda.gov/Drugs/DevelopmentApprovalProcess/DrugInnovation/ucm483775.htm

144. Sidhu PS, Cantisani V, Deganello A, et al. Role of Contrast-Enhanced Ultrasound (CEUS) in Paediatric Practice: An EFSUMB Position Statement. Ultraschall Med 2017;38:33-43.

145. Jacob J, Deganello A, Sellars ME, Hadzic N, Sidhu PS. Contrast enhanced ultrasound (CEUS) characterization of grey-scale sonographic indeterminate focal liver lesions in paediatric practice. Ultraschall Med 2013;34:529-540.

146. Chiorean L, Cui XW, Tannapfel A, et al. Benign liver tumors in pediatric patients - Review with emphasis on imaging features. World J Gastroenterol 2015;21:8541-8561.

147. Menichini G, Sessa B, Trinci M, Galluzzo M, Miele V. Accuracy of contrast-enhanced ultrasound (CEUS) in the identification and characterization of traumatic solid organ lesions in children: a retrospective comparison with baseline US and CEMDCT. Radiol Med 2015;120:989-1001.

148. Oldenburg A, Hohmann J, Skork J, Albrecht T. Imaging of pediatric splenic injury with contrast-enhanced ultrasonography. Pediatr Radiol 2004;34:351-354.

149. Papadopoulou F, Ntoulia A, Siomou E, Darge K. Contrastenhanced voiding urosonography with intravesical administration of a second-generation ultrasound contrast agent for diagnosis of vesicoureteral reflux: prospective evaluation of contrast safety in 1010 children. Pediatr Radiol 2014;44:719-728.

150. Duran C, Riego J, Riera L, Martin C, Serrano C, Palaña P. Voiding urosonography including urethrosonography: high-quality examinations with an optimised procedure using a second-generation US contrast agent. Pediatr Radiol 2012;42:660-667.

151. Sparchez Z, Radu P, Sparchez M, Vasile T, Anton O, Tantau M. Intracavitary applications of ultrasound contrast agents in hepatogastroenterology. J Gastrointestin Liver Dis 2013;22:349-353.

152. Heinzmann A, Müller T, Leitlein J, Braun B, Kubicka S, Blank W. Endocavitary contrast enhanced ultrasound
(CEUS) - work in progress. Ultraschall Med 2012;33:7684.

153. Foschi FG, Piscaglia F, Pompili M, et al. Real-time contrast-enhanced ultrasound - a new simple tool for detection of peritoneal-pleural communications in hepatic hydrothorax. Ultraschall Med 2008;29:538-542.

154. Xu EJ, Zheng RQ, Su ZZ, Li K, Ren J, Guo HY. Intrabiliary contrast-enhanced ultrasound for evaluating biliary obstruction during percutaneous transhepatic biliary drainage: a preliminary study. Eur J Radiol 2012;81:3846-3850.

155. Ignee A, Cui X, Schuessler G, Dietrich CF. Percutaneous transhepatic cholangiography and drainage using extravascular contrast enhanced ultrasound. Z Gastroenterol 2015;53:385-390.

156. Cui XW, Ignee A, Maros T, Straub B, Wen JG, Dietrich CF. Feasibility and Usefulness of Intra-Cavitary ContrastEnhanced Ultrasound in Percutaneous Nephrostomy. Ultrasound Med Biol 2016;42:2180-2188.

157. Luciano DE, Exacoustos C, Luciano AA. Contrast ultrasonography for tubal patency. J Minim Invasive Gynecol 2014;21:994-998.

158. Luciano DE, Exacoustos C, Johns DA, Luciano AA. Can hysterosalpingo-contrast sonography replace hysterosalpingography in confirming tubal blockage after hysteroscopic sterilization and in the evaluation of the uterus and tubes in infertile patients? Am J Obstet Gynecol 2011;204:79.e1-79.e5.

159. Girlich C, Büttner R, Schacherer D, Klebl F. Contrast-enhanced sonographic drainage control: a feasibility study. Z Gastroenterol 2011;49:1470-1474.

160. Sparchez Z, Radu P, Milas M, Tantau M, Vasile T, Anton O. Usefulness of intracavitary application of SonoVue in hepatic and perihepatic fluid lesions. Ultrasound Med Biol 2011;37:S43.

161. Chew SS, Yang JL, Newstead GL, Douglas PR. Anal fistula: Levovist enhanced endoanal ultrasound: a pilot study. Dis Colon Rectum 2003;46:377-384.

162. Zou DZ, Yu YF, Yan DP, et al. Application of contrastenhanced ultrasound in preoperative diagnosis of anal fistula. Chinese Journal of Ultrasonography 2010;19:10511053.

163. Volkmer BG, Nesslauer T, Kufer R, Löffer M, Maier S, Gottfried HW. Diagnosis of vesico-intestinal fistulas by contrast medium enhanced 3-D ultrasound. Ultraschall Med 2001;22:81-86.

164. Chen YJ, Mao R, Xie XH, et al. Intracavitary contrastenhanced ultrasonography to detect enterovesical fistula in Crohn's disease. Gastroenterology 2016;150:315-317.

165. Saftoiu A, Dietrich CF, Vilmann P. Contrast-enhanced harmonic endoscopic ultrasound. Endoscopy 2012;44:612617.

166. Alvarez-Sanchez MV, Napoleon B. Contrast-enhanced harmonic endoscopic ultrasound imaging: Basic principles, present situation and future perspectives. World J Gastroenterol 2014;20:15549-15563.

167. Fusaroli P, Napoleon B, Gincul R, et al. The clinical impact of ultrasound contrast agents in EUS: a systematic 
review according to the levels of evidence. Gastrointest Endosc 2016;84:587-596.e10.

168. Gong TT, Hu DM, Zhu Q. Contrast-enhanced EUS for differential diagnosis of pancreatic mass lesions: a metaanalysis. Gastrointest Endosc 2012;76:301-309.

169. Sidhu PS, Piscaglia F, Cantisani V, et al. The EFSUMB guidelines and recommendations for the clinical practice of contrast enhanced ultrasound (CEUS) in non-hepatic applications: update 2017. Ultraschall Med 2017, in press.

170. Ishikawa T, Itoh A, Kawashima H, et al. Usefulness of EUS combined with contrast-enhancement in the differential diagnosis of malignant versus benign and preoperative localization of pancreatic endocrine tumors. Gastrointest Endosc 2010;71:951-959.

171. Seicean A, Badea R, Moldovan-Pop A, et al. Harmonic Contrast-Enhanced Endoscopic Ultrasonography for the Guidance of Fine-Needle Aspiration in Solid Pancreatic Masses. Ultraschall Med 2017;38:174-182.

172. Gincul R, Palazzo M, Pujol B, et al. Contrast-harmonic endoscopic ultrasound for the diagnosis of pancreatic adenocarcinoma: a prospective multicenter trial. Endoscopy 2014;46:373-379.

173. Imazu H, Kanazawa K, Mori N, et al. Novel quantitative perfusion analysis with contrast-enhanced harmonic EUS for differentiation of autoimmune pancreatitis from pancreatic carcinoma. Scand J Gastroenterol 2012;47:853860.

174. Fusaroli P, Serrani M, De Giorgio R, et al. Contrast Harmonic-Endoscopic Ultrasound Is Useful to Identify Neoplastic Features of Pancreatic Cysts (With Videos). Pancreas 2016;45:265-268.

175. Yamashita Y, Ueda K, Itonaga M, et al. Usefulness of Contrast-Enhanced Endoscopic Sonography for Discriminating Mural Nodules From Mucous Clots in Intraductal Papillary Mucinous Neoplasms: A Single-Center Prospective Study. J Ultrasound Med 2013;32:61-68.

176. Choi JH, Seo DW, Choi JH, et al. Utility of contrastenhanced harmonic EUS in the diagnosis of malignant gallbladder polyps (with videos). Gastrointest Endosc 2013;78:484-493.

177. Kannengiesser K, Mahlke R, Petersen F, et al. Contrastenhanced harmonic endoscopic ultrasound is able to discriminate benign submucosal lesions from gastrointestinal stromal tumors. Scand J Gastroenterol 2012;47:15151520.

178. Rafailidis V, Fang C, Yusuf GT, Huang DY, Sidhu PS. Contrast-enhanced ultrasound (CEUS) of the abdominal vasculature. Abdom Radiol (NY) 2017 Oct 5. doi:10.1007/ s00261-017-1329-7.

179. Catalano O, Lobianco R, Cusati B, Siani A. Contrast-enhanced sonography for diagnosis of ruptured abdominal aortic aneurysm. AJR Am J Roentgenol 2005;184:423427.
180. Saha SA, Gourineni V, Feinstein SB. The Use of Contrastenhanced Ultrasonography for Imaging of Carotid Atherosclerotic Plaques: Current Evidence, Future Directions. Neuroimaging Clin N Am 2016;26:81-96.

181. Rubenthaler J, Reiser M, Clevert DA. Diagnostic vascular ultrasonography with the help of color Doppler and contrast-enhanced ultrasonography. Ultrasonography 2016;35:289-301.

182. Song ZZ, Huang M, Jiang TA, et al. Diagnosis of portal vein thrombosis discontinued with liver tumors in patients with liver cirrhosis and tumors by contrast-enhanced US: a pilot study. Eur J Radiol 2010;75:185-188.

183. Danila M, Sporea I, Popescu A, Sirli R, Sendroiu M. The value of contrast enhanced ultrasound in the evaluation of the nature of portal vein thrombosis. Med Ultrason 2011;13:102-107.

184. Berry JD, Sidhu PS. Microbubble contrast-enhanced ultrasound in liver transplantation. Eur Radiol 2004;14 Suppl 8:P96-P103.

185. Sidhu PS, Shaw AS, Ellis SM, Karani JB, Ryan SM. Microbubble ultrasound contrast in the assessment of hepatic artery patency following liver transplantation: role in reducing frequency of hepatic artery arteriography. Eur Radiol 2004; 14:21-30.

186. Gorg C. Transcutaneous contrast-enhanced sonography of pleuralbased pulmonary lesions. Eur J Radiol 2007;64:213-221.

187. Sartori S, Postorivo S, Vece FD, Ermili F, Tassinari D, Tombesi P. Contrast-enhanced ultrasonography in peripheral lung consolidations: What's its actual role? World J Radiol 2013;5:372-380.

188. Linde HN, Holland A, Greene BH, Görg C. Contrast-enhancend sonography (CEUS) in pneumonia: typical patterns and clinical value - a retrospective study on $n=50$ patients. Ultraschall Med 2012;33:146-151.

189. Bartelt S, Trenker C, Görg C, Neesse A. Contrast-enhanced ultrasound of embolic consolidations in patients with pulmonary embolism: A pilot study. J Clin Ultrasound. 2016;44:129-135.

190. Görg C, Bert T, Kring R. Contrast-enhanced sonography of the lung for differential diagnosis of atelectasis. J Ultrasound Med 2006;25:35-39.

191. Spârchez Z, Radu P, Zaharia T, Kacso G, Grigorescu I, Badea R. Contrast enhanced ultrasound guidance: a new tool to improve accuracy in percutaneous biopsies. Med Ultrason 2010;12:133-138.

192. Cao BS, Wu JH, Li XL, Deng J, Liao GQ. Sonographically guided transthoracic biopsy of peripheral lung and mediastinal lesions: role of contrast-enhanced sonography. J Ultrasound Med 2011;30:1479-1490.

193. Ferrara K, Pollard R, Borden M. Ultrasound microbubble contrast agents: fundamentals and application to gene and drug delivery. Annu Rev Biomed Eng 2007;9:415-447. 